\title{
Lilia Ramos Valverde: presencia en Repertorio Americano
}

\section{Lilia Ramos Valverde: her presence in Repertorio Americano}

\section{Lilia Ramos Valverde: sua presença no Repertório Americano}

\author{
Marybel Soto-Ramírez \\ Coordinadora del Programa Repertorio Americano \\ Instituto de Estudios Latinoamericanos \\ Universidad Nacional \\ Costa Rica \\ Recibido: 23/11/2018 \\ Aceptado: 4/3/2019 \\ DOI: https: //doi.org/10.15359/tdna.35-65.17
}

\section{Resumen}

El presente ensayo propone un acercamiento a los textos de Lilia Ramos Valverde ${ }^{70}$, publicados en Repertorio Americano. Se presenta un corpus conformado por diez textos, de esta brillante autora publicados de 1932 a 1950, los cuales, se propone, brindan claves sobre el pensamiento de una extraordinaria y prolífica intelectual costarricense.

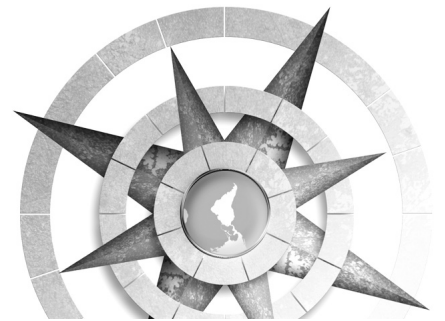

70 1903-1988.
Palabras clave: Lilia Ramos Valverde, Repertorio Americano, escritura de mujeres, pens amiento latinoamericano, pensamiento desde las mujeres.

\section{Abstract}

This essay aims to provide an approach to the writings of Lilia Ramos Valverde that were published in Repertorio Americano by a corpus composed of ten texts that appeared from 1932 to 1950 . These texts shed light on the thought of an extraordinary and prolific Costa Rican intellectual woman, whose work has yet to be fully researched. 
Keywords: Lilia Ramos Valverde, Repertorio Americano, women's writing, Latin American though, female thinking

\section{Resumo}

Este ensaio apresenta uma abordagem aos textos de Lilia Ramos Valverde publicados no Repertorio Americano.

Apresenta um corpus composto por dez textos, publicados de 1932 a 1950 que, propõe-se, fornecem pistas sobre o pensamento de uma extraordinária e prolífica mulher intelectual costarriquenha cujo trabalho precisa ser exaustivamente pesquisado.

Palavras-chave: Lilia Ramos Valverde, Repertorio Americano, escrita de mulheres, pensamento latinoamericano, pensamento feminino

\section{Introducción}

Repertorio Americano, la icónica revista de Joaquín García Monge, circuló ininterrumpidamente de 1919 a 1958; de acuerdo con el investigador Mario Oliva (2011), alcanzó 1181 números publicados, una circulación en toda la geografía americana y allende de ella. Repertorio Americano se constituye como uno de los impresos más longevos de nuestra historia, cuya vocación americanista nucleó y alimentó una red intelectual, conceptualizada como la principal de la primera mitad del siglo XX (Devés-Valdez, 2007).
En esta revista es posible dar seguimiento a una gran variedad de temáticas, pues, tal como señala Prada (1998), es una fuente de investigación de gran riqueza, al reunir lo más selecto de las luces y del pensamiento latinoamericano en sus páginas, a lo largo de casi cuatro décadas de actividad. Precisamente, para la investigadora feminista, el estudio de la producción escrita desde mujeres en la primera mitad del siglo XX y su relación con las revistas culturales como Repertorio Americano es una veta de investigación abierta a partir de la cual se continúa generando trabajos académicos de gran valía sobre temas tan variados como diversas son las temáticas que abarcó el impreso, hoy pronto a conmemorar los cien años de publicación de su primer número.

Prada ha sido enfática en señalar que Repertorio Americano, como tribuna del pensamiento, dio espacio tempranamente a la producción escrita de las mujeres (2002) cuyo aporte a la conformación del pensamiento político costarricense y latinoamericano es plenamente rastreable y comprobable.

En su tesis de posgrado, la antropóloga feminista May Brenes (2004) descubrió un total de 103 textos escritos por mujeres costarricenses y 414 de mujeres latinoamericanas y de otras latitudes, como producción femenina publicada en Repertorio Americano. Asimismo, de acuerdo con la investigadora $\mathrm{Ruth} \mathrm{Cu}$ billo (2001), las mujeres que escribieron 
en la revista fueron vanguardia: ellas rompieron el orden establecido y fijaron su palabra en la dimensión política y social.

Es importante indicar que los escritos elaborados por mujeres que se han identificado en Repertorio Americano, corresponde a textos de géneros diversos; sin embargo, priva en la escritura femenina el género epistolar y el ensayístico. Esta situación no extraña, pues ambos géneros, epístola y ensayo, son formas de lo que se denomina escritura de sí (Foucault 1984) ellos refieren, constantemente, a un punto de vista que se propone para abrir diálogo. La escritura no es una actividad inocente, lleva un sentido político, en tanto se inserta, interpela y busca respuesta en esa res pública y desde ella.

El ensayo, como literatura de ideas, es expresión del pensamiento; por tanto, es muy revelador que precisamente sea este uno de los géneros mediante los cuales una gran cantidad de mujeres se expresara en las páginas de Repertorio Americano. Hay un aspecto de vital importancia, que se debe señalar: la mayoría de estas mujeres eran maestras. Es mi propuesta que las mujeres del magisterio en esta época fueron intelectuales, quienes, a pesar de las restricciones de género, impactaron la esfera pública, cultural y política del país, gracias, precisamente, a su condición de educadoras. La mayor parte de ellas también descollaría, de manera importante como escritoras, gestándose un interesante binomio de maestras con ese oficio, cuya producción ha sido analizada en investigaciones de la historiografía nacional.

Es mi consideración que su oficio de maestras les permitía no solo estar muy al tanto de la situación social del país, a partir de la realidad cotidiana propia en su papel de educadoras, de las familias y las condiciones de la niñez, sino, igualmente, se mantenían informadas, gracias a la lectura y la participación de muchas de ellas en círculos de sociabilidad femenina. Asimismo, ejercieron una gran beligerancia pública; por tanto, en sus textos es posible identificar un gran compromiso con la denominada "cuestión social" que puede entenderse la enorme responsabilidad cívica, en la construcción de ciudadanía. Es importante, asimismo, indicar que, en su condición de maestras, eran mujeres cuya voz tenía una legitimación social y que establecieron prácticas discursivas en la formación de opinión pública.

Lilia Ramos Valverde (1902-1988) fue una de estas mujeres escritoras cuyos textos y pensamiento están presentes en Repertorio Americano. Se identificaron diez textos de su autoría, publicados en el período de 1932 a 1950. Pero, ¿quién fue Lilia Ramos Valverde? ¿por qué sus textos son importantes de estudiarse en pleno siglo XXI? Yadira Calvo la caracteriza como una "vigorosa personalidad (...) una de las escritoras más reconocidas de 
las letras costarricenses" (1987, p.266), al igual que el escritor y especialista en literatura infantil don Carlos Rubio, la reconoce como "una de las destacadas pensadoras del siglo XX” (2019).

Ramos fue maestra, escritora, psiquiatra, mujer de letras, intelectual; una costarricense que dejó escuchar siempre su voz, a partir de la rectitud, la congruencia y del argumento sólido. Graduada como bachiller en Humanidades en el Colegio de Señoritas y también en el Liceo de Costa Rica, su formación universitaria la realizó en Chile, con una beca en el Instituto Pedagógico. Allí estudió Filosofía y Letras.

De regreso a Costa Rica, participó en la Escuela Maternal Montessoriana, fundada por Carmen Lyra, Lilia González y Margarita Castro Rawson. Posteriormente, fue profesora de la Cátedra de Literatura en la Escuela Normal de Costa Rica.

Gracias a una beca en Estados Unidos, Lilia estudió psicoterapia, por lo que se recibió como terapeuta y auxiliar de psiquiatría y se convirtió en especialista en enseñanza para personas ciegas. Fundó en Costa Rica las escuelas para padres y, además, propugnó por que se impartieran lecciones de educación sexual. Exhortó a que la educación sexual iniciara por los padres de familia. Se desempeñó como psicóloga, viajó por Europa, donde ejerció en Francia y España y estudió en Suiza con Jean Piaget.
En Costa Rica destacó en la labor editorial, como Jefe de Publicaciones del Ministerio de Cultura y como cofundadora de la Editorial Costa Rica. Doña Lilia fue la primera mujer costarricense en recibir el Premio Nacional de Cultural, Magón, en 1978.

El acercamiento a su figura permite perfilar las diferentes facetas de esta intelectual costarricense, comprometida con el mejoramiento de la sociedad, por medio de la educación y la cultura, en su más amplio y poderoso sentido, uno de los ejes constantes en su escritura.

Su presencia en Repertorio Americano es importante de investigar para acercarnos a su pensamiento. El corpus que se logró construir a partir de la búsqueda y revisión de la revista, está compuesto por diez textos, seleccionados según propósito de investigación de su pensamiento ${ }^{2}$.

El presente ensayo es resultado de un trabajo mayor de investigación denominado Historia de maestras: la escritura a la sombra de la escuela, inscrito en el Instituto de Estudios Latinoamericanos, que analizó el aporte a la construcción cívica de las mujeres del Magisterio. Presentar la figura de doña Lilia Ramos Valverde en Repertorio Americano

2 No se incluyeron en el corpus los textos que refieren a la partida física de Margarita Esquivel, la gran bailarina, y de Clara Diana, una poeta de época por ser más de tipo panegírico.

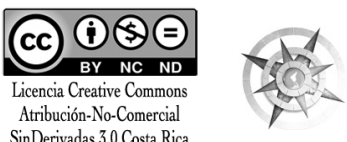


busca ser un aporte a la reconstrucción del pensamiento desde las mujeres en Costa Rica durante la primera mitad del siglo XX.

Lilia Ramos y su análisis de la sociedad La maestra y primera graduada como psicoanalista del país, Lilia Ramos Valverde, (1903-1988) elaboró su eje discursivo fundamentado en la psicología y el psicoanálisis para plantear la necesidad de mejorar los métodos de educación en Costa Rica. Ella consideró firmemente que la educación brindaba una posibilidad de crear un ser humano más completo y, de manera temprana, insistió en la importancia de establecer una relación de afecto y respeto hacia los niños. Ramos analizó los métodos formativos de su época, criticando fuertemente la agresión infantil por parte de las figuras de autoridad como padres y maestros, que incide negativamente en la conformación de un ser humano equilibrado e integral. Basándose en el psicoanálisis, estableció que el castigo físico solo genera en el niño, temor y timidez, asimismo, señaló que rompe, para siempre, la relación cordial de este con las figuras esenciales de su desarro1lo. El refrán, tan extendido en su tiempo, de que la letra con sangre entra, fue destacado como un absurdo que debía combatirse. Doña Lilia propuso que era necesario establecer entre educador y educando un vinculo de relación, de simpatía, afecto y respeto y postuló la educación como un saber científico, no coercitivo, a fin de no crear seres emocionalmente castrados.

En un ejercicio pedagógico, como mente aguda, estudiosa de la realidad, doña Lilia Ramos formuló una relación osada: extendió su postulado a los gobernantes y líderes, como figuras representativas del poder social, en la necesidad de cambiar la idea inadmisible de que con la fuerza bruta se logra respecto y sumisión en los subalternos. Pagaría en carne propia su atrevimiento con amonestaciones y destituciones de puestos docentes, pues fue una mujer que señaló errores y declaró, de forma abierta, su posición y pensamiento.

Sus escritos en Repertorio Americano permiten seguir un itinerario intelectual de esta brillante mujer de letras, en el contexto sociocultural de la primera mitad del siglo XX, en Costa Rica. Su discurso se mantiene asombrosamente fresco para el momento actual que vive el país, en pleno siglo XXI, como veremos a continuación.

\section{Lilia Ramos y Herminia Brumana: las} tizas de colores de la conciencia social

En Tizas de colores, el libro de una educadora (R. A. XXVI, no. 20, 27-5-1933, pp. 317-318) a partir de la reseña del texto de la docente, escritora y periodista argentina, Herminia Brumana, Lilia Ramos analiza la persecución que sufren los educadores cuando mezclan 
enseñanza de ciencias políticas y de ciudadanía en su quehacer, advirtiendo lo que sucede cuando estos contenidos no están sancionados por el poder oficial y los educadores se basan en el análisis de la realidad inmediata, en razón de la cotidianidad que les corresponde vivir, en sus escuelas y comunidades.

Doña Lilia auguraba que los políticos suelen acusar al maestro de confesar su identidad política cuando promueven la concientización social del alumnado y esa es la excusa para destituirlos de sus puestos. Aunque en el escrito Ramos aclaraba que su señalamiento se refería al caso de lo vivido y denunciado por la educadora argentina Herminia C. Brumana, activista social y luchadora por los derechos de las mujeres, destituida de su puesto de maestra en Argentina, es posible proponer que su discurso denota una intencionalidad de mostrar cómo los formadores comprometidos social y políticamente en Costa Rica también experimentaban los mismos problemas. "¿Por qué fue destituida Herminia C. Brumana? Seguramente porque la encontraron educando" ( $\mathrm{p}$. 317), sentenció al inicio de su reseña.

El libro que reseña, Tizas de colores, le fue enviado directamente por la autora desde Argentina. Hay en él una impresionante similitud en estilo escritural y forma con Siluetas de la Maternal de nuestra Carmen Lyra, en el que, a modo de diario escolar, se narran he- chos cotidianos o habituales de profunda sensibilidad social. En ambos casos, se trata de las impresiones de maestras sobre su vivencia escolar, la situación de sus alumnos y su práctica docente.

El tema de la infancia, vinculado con las terribles injusticias sociales y económicas, son denuncias que se hacen patentes a partir de esa realidad social que se cuestiona, desde una posición de compromiso de educadoras y la escuela, la cual nunca debe ser neutra en relación con esas tensiones.

Además de la reseña Ramos incluyó, a texto completo, uno de los pasajes del libro titulado Fiesta patria. El eje discursivo que puede identificarse en este opúsculo permite inferir un tema delicado en la forma de enseñar ciudadanía, o educación cívica, la cual no puede entenderse como memorización o celebración vacía de efemérides. Por el contrario, según señala Ramos, implica el desarrollo del pensamiento crítico del alumnado guiado de los maestros, así como situar las causas que generan la injusticia social, cuyos efectos eran inmediatos en la niñez que tenían a su cargo.

"Porque desde mi cátedra, digo la verdad a mis alumnos y no les declamo que mi país no es el más feliz del mundo, sino que les señalo sus defectos, para que ellos los subsanen (...) No digo que mi patria es poderosa: digo, enseño, cómo 
puede serlo. “(...) en los discursos, frases ampulosas y grandiosas (...) Llego a la escuela y después no sé como viene al caso pero oigo que me cuentan mis alumnos -En mi casa somos cinco y hay dos camas, en una duerme mi mamá, mi papá y mi hermanita. Yo y mi hermano más grande, en el catre..." (p. 327).

Fiesta patria, en forma similar a como lo hizo la costarricense Corina Rodríguez López, denuncia el vaciamiento de contenido de las actividades escolares cívicas de celebración de la independencia y de su desplazamiento a la llana demostración pública del desfile como máxima expresión de civismo.

Lilia Ramos aconsejó la lectura de Brumana a los maestros costarricenses, no sin antes advertirles que los haría identificarse con las problemáticas compartidas por formadores argentinos y de su misma nacionalidad, pues tal era el nivel de denuncia política y social que fácilmente podría pensarse que el libro no fue escrito en Argentina, sino en Costa Rica.

\section{Maestros y patriotismo: de la enseñanza cívica a la práctica social}

Otro de los ejes discursivos que se descubre en los escritos de Ramos, es el patriotismo, que en su crítica es visto más como patrioterismo de signo externo, cuando se demerita lo nacional, se desprecian los productos propios del país, se prefiere lo extranjero y se defrauda al pueblo que paga con sus impuestos el sueldo de los políticos y burócratas, con su ineficiente trabajo.

De acuerdo con la pensadora, el papel de compromiso cívico del maestro se enarbola desde la libertad de cátedra, la responsabilidad social, y el análisis de la realidad, que es lo propio de su práctica docente. La enseñanza cívica y la práctica social son uno solo en la propuesta que formula.

Al citar una conversación con el diplomático argentino don Arturo Urién, benefactor de la educación costarricense y de los proyectos de Carmen Lyra, Ramos ejemplifica ese indisoluble lazo pedagógico entre práctica y reflexión que es la acción cívica de los maestros. Ella nos dice:

El maestro debe, según su parecer, pensar cada día en su patria, con el propósito de buscar medios de dignificarla, de ennoblecerla, pues únicamente así se puede ser capaz de formar en los niños el verdadero orgullo ciudadano. Yo, que tampoco creo en esas jornadas de civismo en que se dicen mentiras en formas muy bellas, le pedí a mi amigo una idea para celebrar un 15 de setiembre. -Funde una biblioteca, me dijo. - Vaya a la librería Lines 
y escoja veinte volúmenes interesantes y que me pasen la cuenta. Además, agregó, dé la sugestión a otra maestra, para que funde un botiquín en esa misma fecha. Las boticas de la ciudad le darán muchas cosas que en esa escuela de ustedes hacen falta. Ambas ideas se llevaron a cabo (R. A. XXI, no. 3, 23-7-1932, p. 48).

La densidad del pensamiento político de Ramos se ejemplifica cuando declaró que eran palabras vacías de contenido y expresión "...patria, patriotismo, elevado espíritu cívico, respeto a la ley y a las instituciones" (R. A. XXVI, no. $8,27-7-1932$, p. 48) y de muchos autoproclamados beneméritos de la patria, a los cuales, con ironía llamó maleméritos, pues "su avaricia únicamente los ha llevado a usar la patria como mercancía para venderla al mejor postor" (R. A., no. 8, 27-7-1932, p. 48).

Es ineludible que el conocimiento de los hechos del mundo afina la conciencia de las personas, en especial, de los maestros, pero se requiere valor para cambiar un estado injusto de cosas, por ello, declaraba:

Patria. Patriotismo. ¿Qué dicen estas palabras a un escolar o a un estudiante de segunda enseñanza? ¿Qué nos han enseñado nuestros maestros de Educación Cívica? (...) nociones acerca de los orígenes de nuestra ponderada libertad, sobre la organización de un Estado y de su excelencia (aunque haya gran número de personas muriendo de hambre y [se estén] gastando miles de colones en fiestas,), etc. La culpa no es de los maestros. Sabemos el grave, gravísimo peligro que se corre cuando a alguno se le ocurre salirse del camino que indica la Pedagogía oficial ( R. A . XXVI, no. 8, 27-7-1932, p. 48).

De similar manera, plantearía en su crítica el peligro del prejuicio y el costo que lleva, desmontar esas ideas que por falta de ponerlas en tela de juicio, ya por no tener las herramientas necesarias para ello o sobre todo, por ser acomodaticios al sistema, se perpetúan en nuestra cultura: "Los prejuicios forman una costra impermeable que produce una fobia por todo lo nuevo, por todo aquello que tienda a cambiar el estado de cosas y, a fin de cuentas, lo que impide la penetración de la realidad en nuestro espíritu”. (R.A. XXIV no. 8, 5-3-1932, p. 128). Con estas palabras introduciría en "Hay que leer esos libros", la necesidad de referirse a un tema "escabroso", en su momento, que hacia girar sobre sí, "los más absurdos prejuicios: cuestión sexual" (p.128). Cifraba en los maestros la responsabilidad de atender esta temática, pero su concepción de estos facilitadores no se circunscribía al magisterio, sino a padres de familia, a sacerdotes y a todos los que les corresponde educar. 
Su artículo llama la atención porque declara no buscar ahondar en un tema tan difícil, sin embargo, apunta a una serie de "obras que en mi condición de maestra me he obligado a leer con atención”, seguidamente señalará que son libros que "humanizan y proporcionan un excelente material para nuestra labor educativa" (p. 128). De esta forma, propongo, salvaguarda su posición sobre un tema que era profundamente polémico y cuya expresión en lo público, podría acarrear precisamente, posturas prejuiciadas que buscaba atacar. Ramos presenta así una selección de obras que abordan diferentes temáticas, entre las cuales, destaca: vida sexual estados intersexuales, evolución de la sexualidad, rebelión de la juventud, patologías y moral sexual.

Desde Bertrand Russell a Sigmund Freud, brindaría diferentes enfoques, no sin antes entrar en diálogo con el padre del psicoanálisis y sus teorías controversiales, amonestando que: "Dentro de medio siglo, quizá menos, se reconocerá al psicoanálisis todo el valor científico que posee" (p. 128).

Recomendar lecturas sobre sexualidad en un medio escrito en 1932 requeriría de una personalidad fuerte y muy segura. Si bien Lilia Ramos lo hace asumiéndose desde un papel pedagógico, no cabe duda de que el riesgo de exponerlo públicamente era grande. Es importante recordar que doña Lilia estableció las escuelas para padres y que sería otra grandiosa mujer, cuya figura, aporte y pensamiento aún permanece muy a la sombra de su esposo y que requieren de mayor investigación, María Teresa Obregón, quien valientemente abriría clases de educación sexual para padres y para jóvenes, en la ciudad de Heredia.

Este texto de Ramos debe resaltarse pues cierra su intervención señalando la obra "de una mujer que ha escrito sobre la cuestión sexual: Ellen Key. (...) quien expone francamente sus ideas desde el punto de vista femenino" (p. 128). ¿Qué pretendía doña Lilia Ramos deslizar en su escrito al proponer en su discurso la visión desde lo femenino, la visión de la diferencia y la diversidad, entre una serie de intervenciones de científicos y académicos, sobre el tema sexual? Solo el hecho de dejar esta temática planteada es un ejercicio transgresor para su época. Luchar contra el prejuicio en todo aspecto, alcanza aquello que es lo más primigenio para abrirse al conocimiento y lo justifica, según mi apreciación, desde el epígrafe con el que Lilia abre su texto, citando a Gregorio Marañón (1932: p. 128): “...y la moral? se nos dirá. Por la moral, contestamos, no hay que preocuparse. La moral -la eterna y divina moral, no la que han inventado los fariseos- está siempre al lado de la luz".

En Balanza de palabras y hombres, enfrentamos un texto de corte antiimperialista, donde dirige su crítica a los 
maestros rutinarios que dictan lecciones aburridas, sin darle nunca a sus alumnos el papel activo que merecen en la relación pedagógica. Estos maestros, para pensadora, eran incapaces de aceptar la más mínima crítica, manteniendo, de esa forma, el estado de cosas en la mediocridad. Asimismo, señaló a la "prensa burguesa" que "quiere dorar la píldora y reproduce discursos de los llamados grandes políticos o panegíricos de estos" (R. A. XXVI, no. 8, 27-7-1932, p. 48) en detrimento de la realidad social, del análisis de los problemas del pueblo, con el verdadero interés de buscar soluciones.

Al margen de una carta reveladora (R. A. XL, no. 7 10-4-1943 p. 110-101) es un texto donde promulga la importancia de la psicología y el niño. Presenta el caso del escritor Franz Kafka y el vínculo extremo que tuvo con su padre, para indicar que es necesaria una verdadera preocupación del educador por apoyar a sus alumnos en las situaciones difíciles. El ejercicio del trabajo docente, más allá de una forma de ganarse de vida, es una vocación, por lo que para nuestra pensadora laborar con convicción, es una muestra cívica de vivencia personal.

Lilia Ramos Valverde, como puede desprenderse, fue una mujer de pensamiento crítico y pluma directa. En sus textos está presente un fuerte cuestionamiento a las nociones de educación no científica, falta de vocación y sojuzgadora del espíritu infantil y de una forma- ción cívica que, en vez de instruir ciudadanos sólidos y críticos, alecciona en el patrioterismo y forma en la sumisión. Lilia declaraba que esos aspectos son en realidad de muy poca ayuda a la democracia y por tanto, son claros facilitadores de manejos políticos turbios ante ciudadanos que no cuestionan. Por ello su pregunta constante de a quién sirve este tipo de ciudadanos y a quien sirve este tipo de educación.

También cuestionaba a la sociedad gazmoña que desprecia los nuevos valores literarios que no estén acordes con los cánones establecidos, el poco espacio que se brinda a los jóvenes talentos y sus escasas oportunidades de surgir. Reseñaba las figuras de personajes que con su actuar y su compromiso, debían ser ejemplo de ciudadanía, en vez de oscurecer sus logros o sospechar sobre sus intensiones. Y sobre todo, reprochaba a la pedagogía oficial por oscurecer el sentido amplio de libertad, de ciudadanía, de ser humano integral a las que sus programas aseguraban aspirar, y mostraba, en contrate, los muchos retos a los que estaban expuestos los educadores comprometidos con un cambio de ese paradigma y con el mejoramiento social. Tal era la realidad que analizó, criticó y plasmó la mente brillante de esta maestra e intelectual costarricense, cuyos escritos publicados en Repertorio Americano, de 1932 a 1950, nos brindan claves de un pensamiento, pertinente y fresco, para nuestro siglo XXI. 
Lilia Ramos Valverde

Escritos publicados en Repertorio Americano según tipo de texto

\begin{tabular}{|l|l|l|}
\hline \multicolumn{1}{|c|}{ Título } & \multicolumn{1}{|c|}{ Referencia } & Tipo de texto \\
\hline $\begin{array}{l}\text { Sin noviciado. Yolanda } \\
\text { Oreamuno escribe obra } \\
\text { psicoanalítica }\end{array}$ & $\begin{array}{l}\text { R. A. XLVI, no. 12, 20-6- } \\
1950, \text { pp. 185-188. }\end{array}$ & Ensayo \\
\hline $\begin{array}{l}\text { Silueta de Nina Bull } \\
\text { (incluye traducción del } \\
\text { artículo de la insigne } \\
\text { psicóloga) }\end{array}$ & $\begin{array}{l}\text { R. A. XLIV, no. 17, 20-12- } \\
1948, \text { p. 258. }\end{array}$ & Reseña \\
\hline Xochimilco & $\begin{array}{l}\text { R. A. XLI, no. 15, 12-11- } \\
\text { 1945, p. 240. }\end{array}$ & Ensayo \\
\hline Alfredo Cardona Peña & $\begin{array}{l}\text { R. A. XLI, no. 15, 12-11- } \\
1945, \text { p. 240. }\end{array}$ & Ensayo \\
\hline $\begin{array}{l}\text { Al margen de una carta } \\
\text { reveladora }\end{array}$ & $\begin{array}{l}\text { R. A. XL, no. 7, 10-4-1943 } \\
\text { pp. 110-101. }\end{array}$ & Ensayo \\
\hline $\begin{array}{l}\text { Tizas de colores, el libro } \\
\text { de una educadora }\end{array}$ & $\begin{array}{l}\text { R. A. XXVI, no. 20, 27-5- } \\
\text { 1933, p. 317. }\end{array}$ & Reseña \\
\hline $\begin{array}{l}\text { Balanza de palabras y } \\
\text { hombres }\end{array}$ & $\begin{array}{l}\text { R. A. XXVI, no. 8, 27-7- } \\
1932, \text { p. 48. }\end{array}$ & Ensayo \\
\hline $\begin{array}{l}\text { Siempre recordaremos a } \\
\text { don Arturo Urién }\end{array}$ & $\begin{array}{l}\text { R. A. XXV, no. 3, 23-7-1932 } \\
\text { p. 48. }\end{array}$ & Ensayo \\
\hline $\begin{array}{l}\text { Un revolucionario del } \\
\text { Medioevo }\end{array}$ & $\begin{array}{l}\text { R. A. XXIV, no. 15, 30-4- } \\
1932, \text { p. 128. }\end{array}$ & Ensayo \\
\hline Hay que leer estos libros & $\begin{array}{l}\text { R. A. XXIV no. 8, 5-3-1932, } \\
\text { p. 128. }\end{array}$ & Ensayo \\
\hline
\end{tabular}




\section{Referencias bibliográficas}

Calvo, Y. (1987). Lilia Ramos. Maestra y escritora. Revista Iberoamericana. LIII (138-139), pp.265-279. DOI: https://doi.org/10.5195/ reviberoamer.1987.4327

Cubillo, R. (2001). Mujeres e identidades. Las escritoras de Repertorio Americano (1919-1959). San José: EUCR.

(2011). Mujeres ensayistas e intelectualidad de vanguardia en Cota Rica de la primera mitad del siglo XX. San José: EUCR.

Devés-Valdez, E. (2007). Redes intelectuales en América Latina. Chile: Idea.

Foucault, M. (1984). Las palabras y las cosas. Barcelona: Agoustini

Oliva, M. (2011). Repertorio Americano (1919-1958). Producción, circulación y lectores. Repertorio Americano. No. 21 (Segunda Nueva Epoca, enero-diciembre) pp. 21-96.

Prada, G. (2011). Repertorio Americano, tribuna del pensamiento latinoamericano. La voz de José Vasconcelos. En Repertorio Americano. (21), pp. 21-96
(2010). El pensamiento filosófico desde las mujeres. Matilde Carranza, Vera Yamuni y Ana Isabel Alfaro. Costa Rica: EUNA. (2002). Mujeres forjadoras del pensamiento costarricense. Ensayos femeninos y feministas. [Tesis doctoral]. Universidad Nacional, Heredia, C.R

Rubio, C (31 de marzo de 2019). Lilia Ramos o el diáfano lenguaje de la belleza. La Nación. Recuperado de https://www.pressreader.com/ 